\title{
Web Enabled Real Time Weather Data Analysis
}

\author{
P. Sardar Maran ${ }^{1 *}$ and R. Ponnusamy ${ }^{2}$ \\ 'Research Scholar, Sathyabama University, Chennai, India; sardarmaran@gmail.com \\ 2Principal, Madha Engineering College, Kundrathur, Chennai, India; rponnusamy@acm.org
}

\begin{abstract}
In this paper, a web enabled software tool is developed for Meteorological Information System, with Query, Visualization and Data Reporting features for the Meteorological Network. A state of the art Data Acquisition System has (DAS) been designed and implemented at 50m Meteorological Tower in Chennai. This tool is used to generate the multilevel micrometeorological data with tower based measurements and provide the same for wind field modeling studies. The salient feature of the $50 \mathrm{~m}$ meteorological tower has been established to receive real time meteorological data for predicting research based models in both academic and industries.
\end{abstract}

Keywords: Meteorological Data, Weather-info, Real-time Weather.

\section{Introduction}

Weather forecasting is very important in recent years of science and technology to predict the state of the atmosphere for a future time and a given location. Surface weather observations are the fundamental data used for safety as well as climatologically reasons to forecast weather and issue warnings worldwide. Human beings have attempted to predict the weather informally for millennia, and formally since at least the nineteenth century. Weather forecasts are made by collecting quantitative data about the current state of the atmosphere and using scientific understanding of atmospheric processes to project how the atmosphere will evolve.

In this paper we present a broad overview of computational weather prediction and analysis the use of meteorological data for atmospheric flow model. In this study, various locations of tower data have been used in several kinds of analyses with different goals. Meteorological towers are the platforms providing continuous in situ information within the lower atmospheric layer. The future state of the atmosphere could be predicted with the help of weather forecasting. Surface weather observations are the fundamental data used for safety as well as climatological reasons to forecast weather and issue warnings worldwide.

\section{About Meteorological Tower}

Meteorological (and related environmental and geophysical) observations are made for a variety of reasons. They are used for the real-time preparation of weather analyses, forecasts and severe weather warnings, for the study of climate, for local weather dependent operations (for example, local aerodrome flying operations, construction work on land and at sea), for hydrology and agricultural meteorology, and for research in meteorology and climatology.

Meteorological data have been used in several kinds of analyses with different goals. Meteorological towers are the platforms providing continuous in situ information within the lower atmospheric layer. The $50 \mathrm{~m}$ tower at Sathyabama University has multilevel sensors for all the basic atmospheric parameters like wind speed and

*Corresponding author:

P. Sardar Maran (sardarmaran@gmail.com) 
direction, temperature, relative humidity, pressure, rainfall and nuclear radiation. The data from this tower will be used in real time for site-specific, on-line dispersion modeling and prediction at IGCAR as well as for basic studies on mesoscale sea-land breeze circulation. The following Table 1. shows the installed sensors in the $50 \mathrm{~m}$ tower.

\section{Objective and Methodology}

The main objective of this work is to monitor Surface Weather Observation data for wind speed, wind direction, relative humidity, temperature, pressure and background nuclear radiation. The weather observation data is used to archive for basic research in fundamental areas of atmospheric sciences [4-6]. As a usual practice emergency drills are conducted periodically at Kalpakkam to keep the management familiar and comfortable to handle such events at any point of time and for this the tower facility at Sathyabama University can contribute for efficient organization of the emergency management system by way of giving direction of evacuation in real-time. The wind load analysis and review wind load standards particularly for coastal structures to find out the gap in the methodology and data.

\section{Methodology}

A data retrieval and display software will be developed that will have capabilities to query the raw meteorological data from different existing Met Towers at IGCAR, Sathyabama and provide data report in user required format. The queries can be based on parameters, date \& time range, level of measurement and the instruments. The data can be saved in either standard ASCII format or in data base Excel or Dbase formats. The Web-based application will be initially ported on the Sathyabama domain and later will be transferred to IGCAR portal.

The weather data is automatically saved in the data server from the data loggers. Microsoft SQL server software will be used for storing and retrieval of data. Application for accessing the data from the web portal will be developed by using Microsoft ASP.NET software for getting dynamic weather data from the server. Programming code will be developed for communicating between server and the application.

\subsection{Technical Details}

1. Data will be logged in the Data Logger system using DASYlab 8.0 Software at every 10 minutes from the meteorological tower.

2. Using Serial Communication port the data will be read as a single bit at a time to the Windows 2003 Server using Visual Basic program.

3. At the same time the data will be loaded in a data base using SQL Server Data base tool.

4. Using various simulation and data analysis tools the meteorological weather data will be worked out as a Meta data files, 3D formats and graphs with user interface.

\subsection{Data Acquisition}

1. Wind Speed and Direction

2. Temperature

3. Humidity

Table 1. List of sensors installed in the $50 \mathrm{~m}$ tower

\begin{tabular}{|c|c|c|c|c|c|}
\hline Sl. No & Parameter Measured & Type/Make & Range & $\begin{array}{c}\text { Installed } \\
\text { Levels (in m) }\end{array}$ & $\begin{array}{l}\mathrm{O} / \mathrm{P} \text { Range in } \\
\text { volts }\end{array}$ \\
\hline 1 & Wind Speed & $\begin{array}{l}\text { NRG\#40 } \\
\text { Hall Effect }\end{array}$ & $\begin{array}{c}1 \mathrm{~m} / \mathrm{s} \text { to } 96 \\
\mathrm{~m} / \mathrm{s}\end{array}$ & $2,8,16,32,50$ & $\begin{array}{l}\text { Digital } \\
\text { Pulses }\end{array}$ \\
\hline 2 & Wind Direction & NRG\#200P & $\begin{array}{l}0 \text { to } 350 \\
\text { Degrees }\end{array}$ & $2,8,16,32,50$ & 0 to $5 \mathrm{~V}$ \\
\hline 3 & RH \& Temperature Sensor & $\begin{array}{l}\text { Rotronic MP } \\
100 \mathrm{H}\end{array}$ & $-40 \mathrm{C}$ to $+50 \mathrm{C}$ & $2,8,16,50$ & 0 to $5 \mathrm{~V}$ \\
\hline 4 & Atmospheric Pressure & $\begin{array}{l}\text { RM Young } \\
61202 \mathrm{~V}\end{array}$ & $\begin{array}{c}800 \text { to } 1060 \\
\mathrm{hPa}\end{array}$ & Surface & 0 to $5 \mathrm{~V}$ \\
\hline 5 & Precipitati on & $\begin{array}{l}\text { RM Young } \\
61202 \mathrm{~V}\end{array}$ & $0.1 \mathrm{~mm} /$ pulse & Surface & $\begin{array}{l}\text { Digital } \\
\text { Pulses }\end{array}$ \\
\hline 6 & Nuclear Radiation & $\begin{array}{l}\text { GM Tube } \\
\text { ZP1220/01 }\end{array}$ & $\begin{array}{l}0 \text { to } 3000 \\
\text { usv/h }\end{array}$ & Surface & - \\
\hline
\end{tabular}


4. Pressure

5. Radiation

\subsection{Software Tools}

\subsubsection{ASP.NET}

ASP.NET allows you to use a full featured programming language such as C\# (pronounced C-Sharp) or VB.NET to build web applications easily. Unfortunately, the Internet still has bandwidth limitations and not every person is running the same web browser. These issues make it necessary to stick with HTML as our mark-up language of choice. This means that web pages won't look quite as amazing as a fully fledged application running under Windows, but with a bit of skill and creative flair, you can make some rather amazing web applications with ASP. NET. ASP.NET processes all code on the server (in a similar way to a normal application). When the ASP.NET code has been processed, the server returns the resultant HTML to the client. If the client supports JavaScript, then the server will use it to make the clients browser experience quicker and easier. Even with HTML being the limiting factor here, ASP.NET still manages to bring true OOP (Object Oriented Programming) to the Internet. $[7,8]$

\subsubsection{OOP on the Internet}

Object Oriented Programming (OOP) makes it possible to build extremely large applications, while still keeping your code clean and structured. Now with ASP.NET, we can do the same on the web. Traditional, ASP uses HTML and VBScript (or Jscript) to process and render pages, but because VBScript is a scripting language, you were forced to write spaghetti code (VBScript was entwined in the HTML and ended up rather messy in larger applications). ASP.NET separates code from display, and you can even have pages with no ASP.NET code in them at all. By adding references in your HTML (called controls), you can tell ASP.NET that you want a button here, some text there, and then in your code, you can manipulate what these controls look like, what they display, how big they are, etc. Controls can do more than just display information. You can add events to controls, so that when a visitor clicks on a button, for example, ASP.NET executes a function of your choice.

\subsubsection{Web Services}

One great feature of ASP.NET is Web Services. Web services mean that you can literally have several pieces of your application on different servers all around the world, and the entire application will work perfectly and seamlessly. Web services can even work with normal .NET Windows applications. For example: A lot of people would like to have a stock ticker on their web site, but not many people want to manually type in all changes to the prices. If one company (a stock broker) creates a web service and updates the stock prices periodically, then all of those people wanting the prices can use this web service to $\log$ in, run a function which grabs the current price for a chosen company, and return it. Web services can be used for so many things: news, currency exchange, login verification... The ways in which they can be used are limited to your imagination! $[2,3]$

\subsubsection{Great XML Support}

ASP.NET makes it simple to use XML for data storage, configuration and manipulation [1]. The tools which are built into ASP.NET for working with XML are very easy to use. XML is excellent for storing information that rarely changes, because you can just cache that information in the computer's memory after it has been initially extracted.

\subsubsection{Class Library}

ASP.NET includes an enormous class library which was built by Microsoft. Because this class library is so large, it encapsulates a huge number of common functions. For example, if you wanted to retrieve data from a database and display that data in a simple grid control through classic ASP, then you'd have to write quite a lot of code. In ASP.NET, you don't write any code to display the data you just write the code to bind the data to an object called a Data Grid (which can be done in just a couple of lines). Then, you just have to create a reference on your page to where that Data Grid should go. The Data Grid will be rendered as a table, and will contain all of the data extracted from the database.

\section{Results}

The following figures 2, 3 and 4 show the web pages of online weather information system. The first page in the Figure 1 shows the meteorological tower locations (i.e. Sathyabama University, SRM University, Kalpakkam Anupuram, Kalapakkam IGCAR main Gate, Annamalai University etc.). 


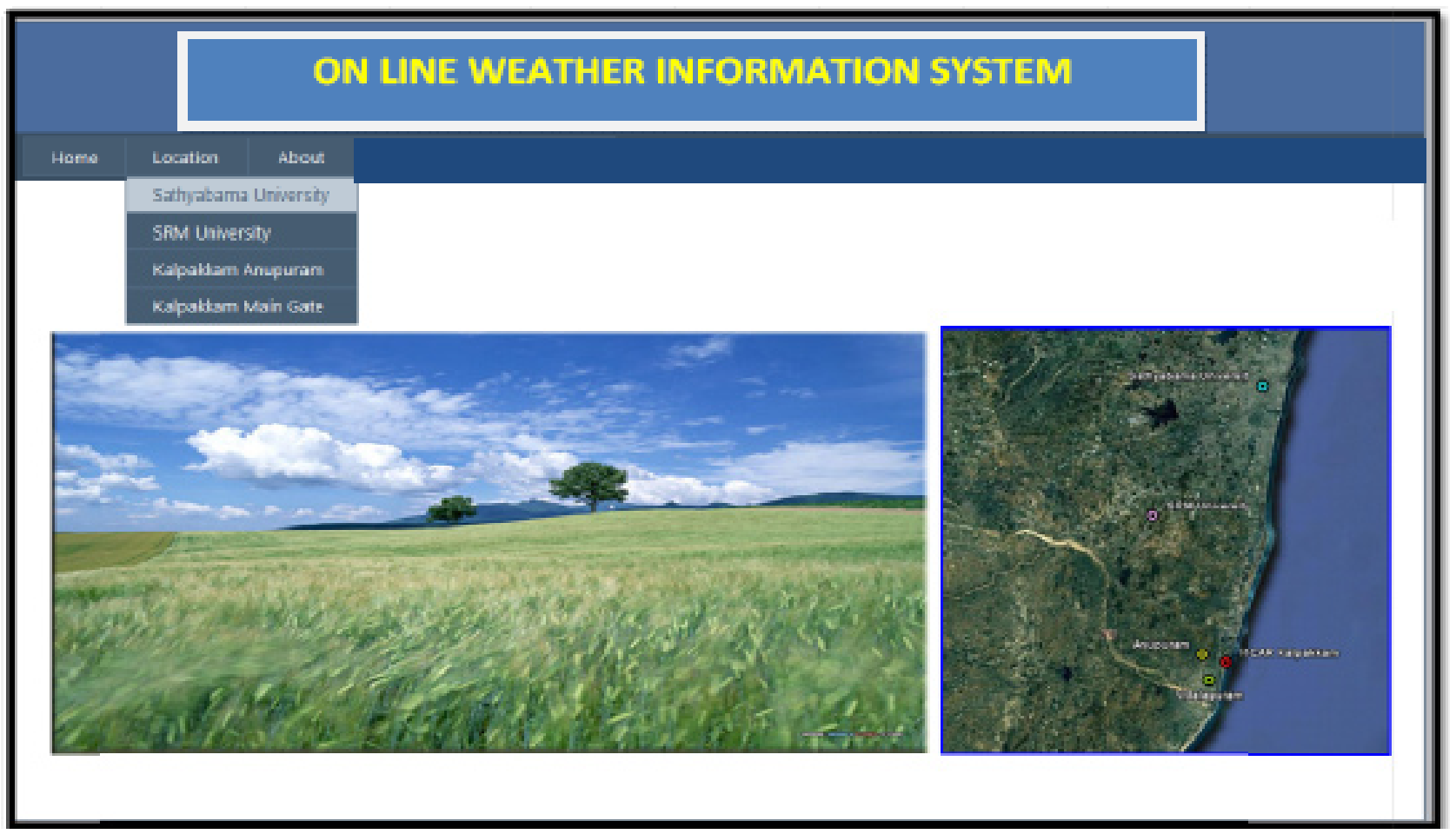

Figure 1. Main page of OWIS showing tower locations.

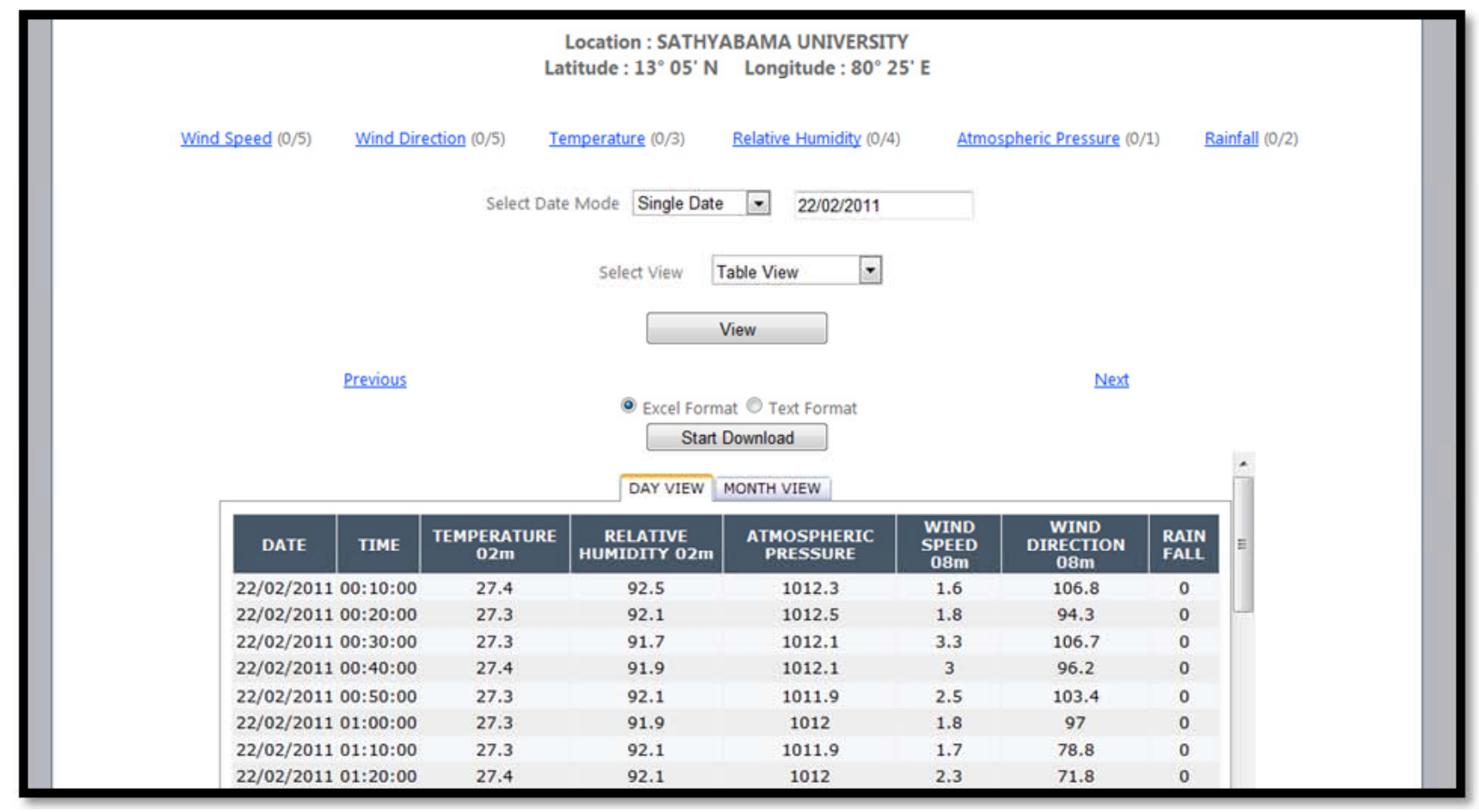

Figure 2. Data range and view selection for a particular location. 
Location : SATHYABAMA UNIVERSITY

Latitude : $13^{\circ} 05^{\prime} \mathrm{N}$ Longitude : $80^{\circ} 25^{\prime} \mathrm{E}$

\begin{tabular}{ll}
\hline Present Date & $22-02-2011$ \\
Present Time & $02-12-57$ PM \\
Updated Before & 13 Minutes \\
Temperature & $27.6^{\circ} \mathrm{C}$ \\
Wind Speed & $3.2 \mathrm{~m} / \mathrm{s}$ \\
Wind Direction & $45.1 \mathrm{NE}$ \\
Realtive Humidity & $100.9 \%$ \\
Atmospheric Pressure & $1011.2 \mathrm{mbar}$ \\
Rain Fall & $34.6 \mathrm{~mm}$ \\
\hline
\end{tabular}

Wind Speed $(0 / 5) \quad$ Wind Direction (0/5)

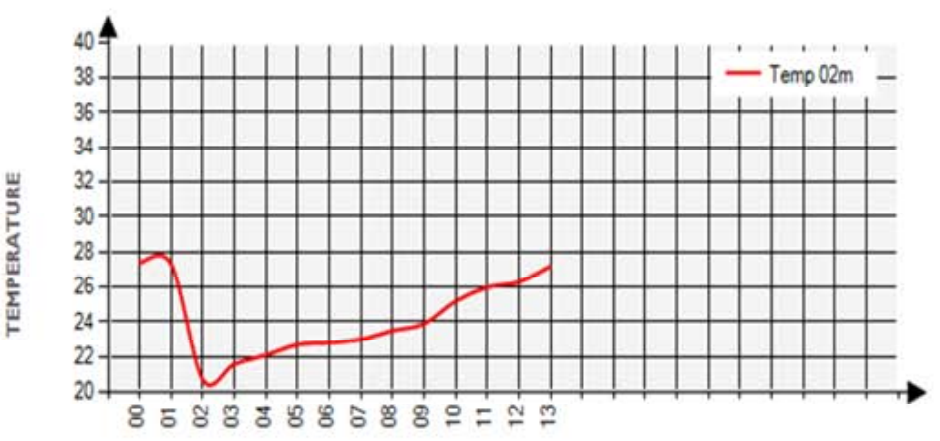

TIME-HOURS

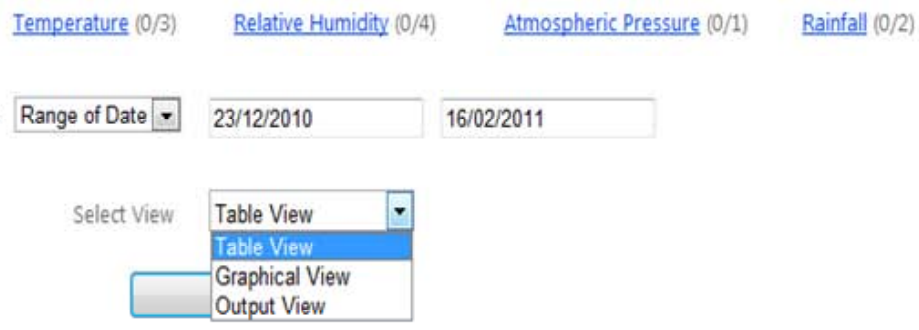

Figure 3. Data range and view selection for a particular location.

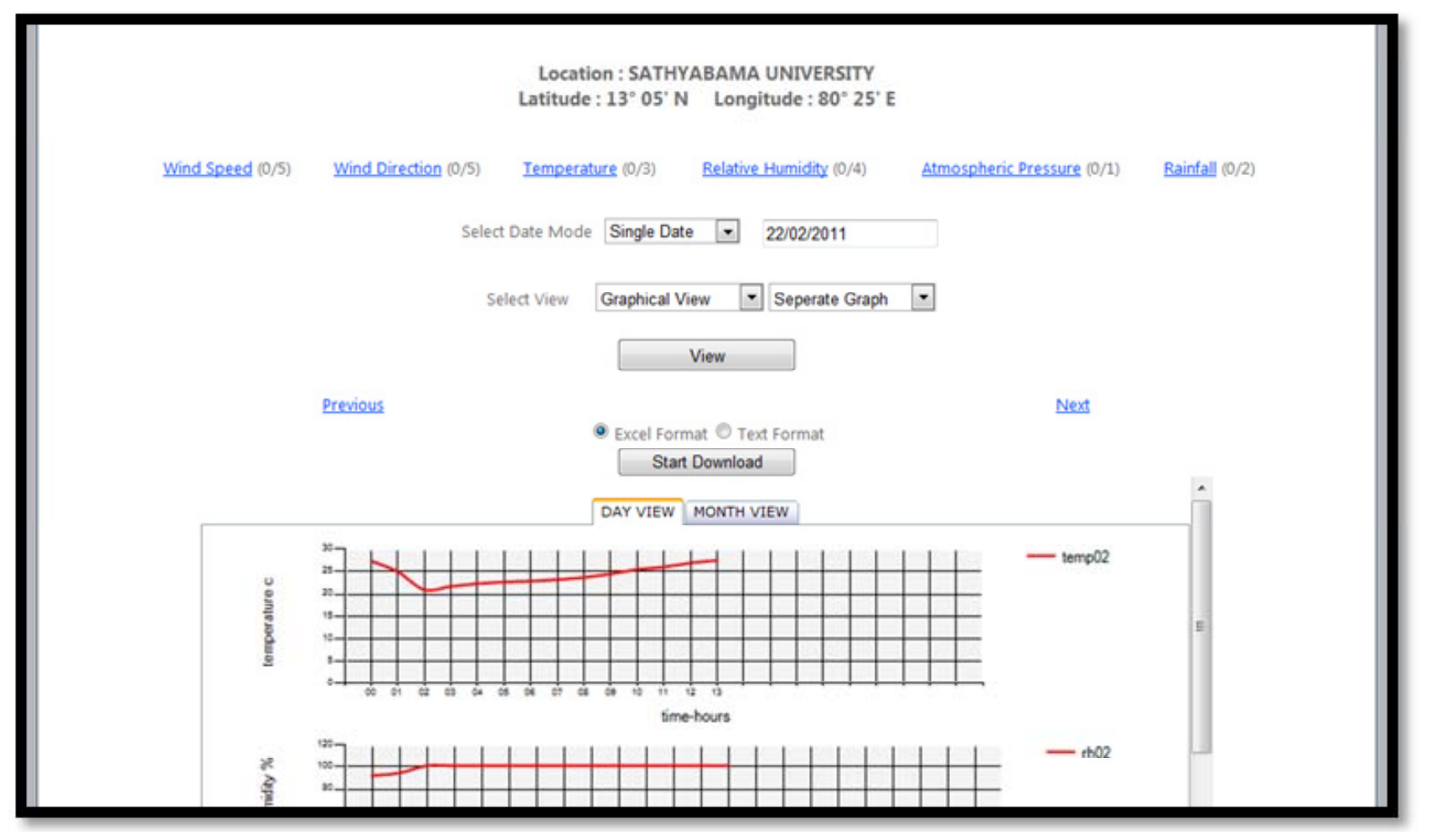

Figure 4. Multiple weather parameter selection in a graphical view. 


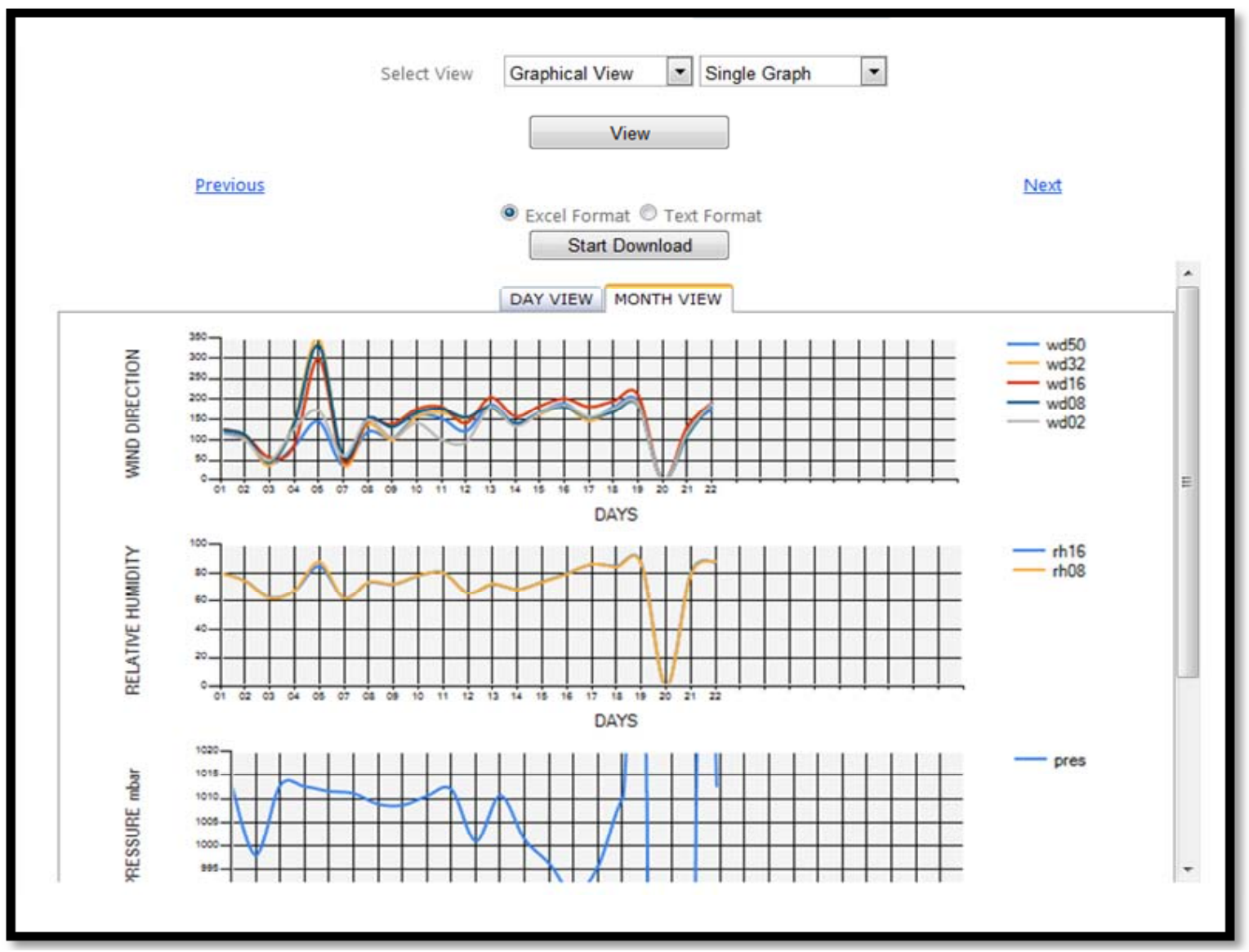

Figure 5. Multiple weather parameter selection for a month.

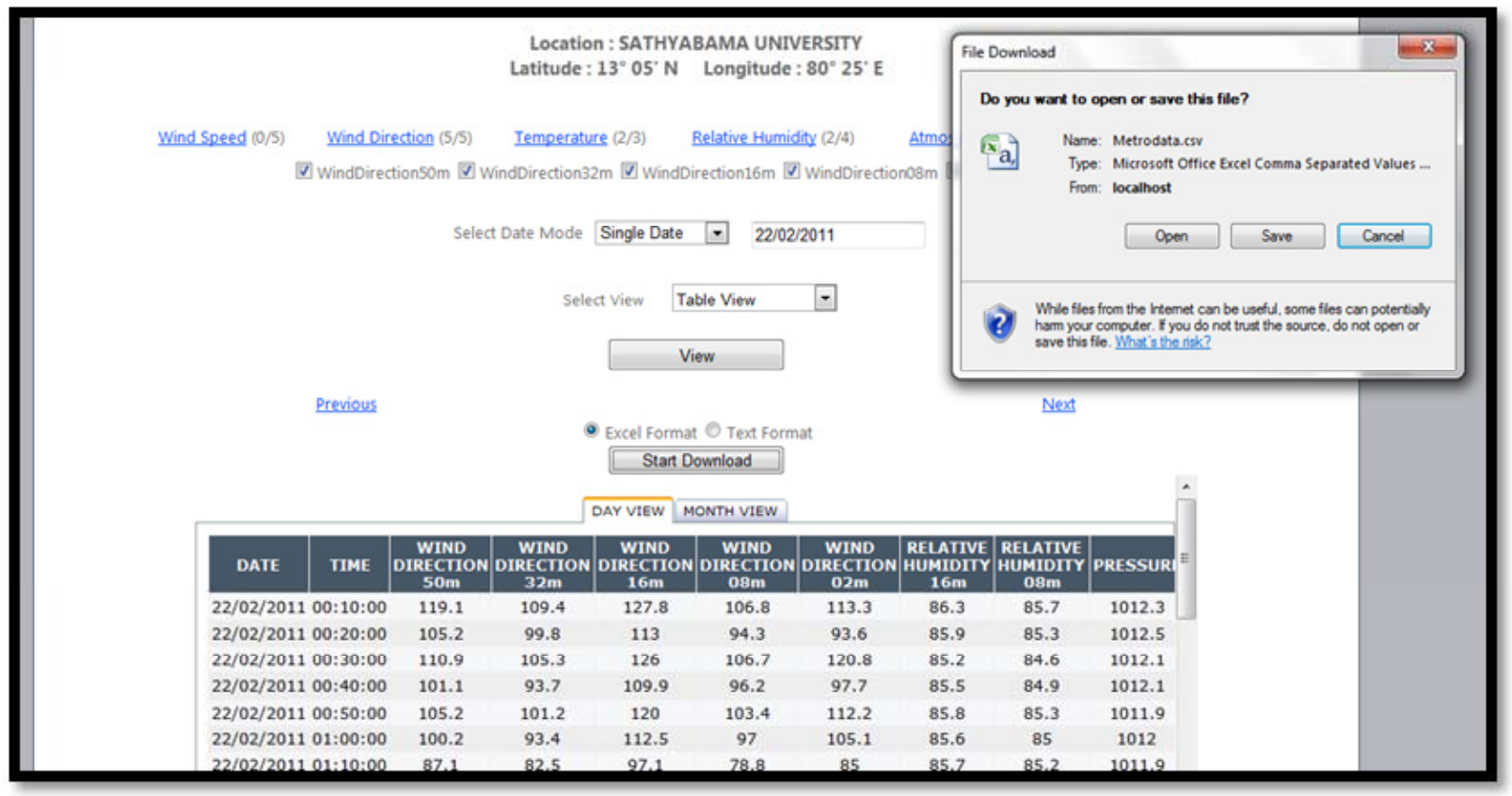

Figure 6. Data archival and downloading system. 


\section{Conclusion}

A state of the art Data Acquisition System has (DAS) been designed and implemented at 50m Meteorological Tower in Sathyabama University, Jeppiaar Nagar, Chennai. The system has a number of novel features, which includes configuration, based on readily available modules. The heart of the system can be any personal computer or industrial computer thus enabling the user to configure the DAS in any computer of his choice. This makes usage of dedicated system a thing of the past. The system has been installed and commissioned successfully. The salient feature of the $50 \mathrm{~m}$ meteorological tower has been established to receive real time meteorological data for predicting research based models in both academic and industries.

\section{References}

1. Liu L, Pu C et al. (2001). An XML-enabled data extraction toolkit for web sources, Information Systems, vol 26, 563-583.
2. Chassiakos A P, and Sakellaropoulos S P (2008). A webbased system for managing construction information, Department of Civil Engineering, University of Patras, Patras, Greece vol 39(11), 865-876.

3. Smith M T, and Lakshmanan V (2011). Real-time, rapidly updating severe weather products for virtual globes, Computers \& Geosciences, vol 37(1), 3-12.

4. Sun X, Shen S et al. (2012). Development of a webbased visualization platform for climate research using google earth, Computers \& Geosciences, vol 47, 160-168.

5. Desai R G P, Joseph A et al. (1999). Internet-accessible real-time weather information system, SYMPOL-'99, Proceedings of the National Symposium on Ocean Electronics, 47-54.

6. Real Time Weather Forecast Information System (20082009). Annual Report of, Centre for Development of Advanced Computing (C-DAC), Pune.

7. Available from: http: //www.symphonyinfotech.co.in/ about_asp.php

8. Available from: http: //jskharay.wordpress.com/2010/09/25/ what-is-asp-net 